\title{
A 400 AÑOS DEL FALLECIMIENTO DE FRANCISCO SUÁREZ. SIMILITUDES ENTRE EL IUSNATURALISMO MODERNO Y EL CONTEMPORÁNEO
}

\author{
Carlos PATIÑo GutiérReZ*
}

\author{
Sumario: I. Introducción. II. La escolástica. III. Un comentario \\ marginal. IV. La discusión contemporánea. V. Las contribuciones \\ suarecianas. VI. Conclusión.
}

\section{INTRODUCCIÓN}

Este artículo sostiene que los planteamientos de algunos autores iusnaturalistas recientes, cuyas premisas pueden parecer muy novedosas, en realidad forman parte de una añeja tradición de pensadores. Se trata de una comunidad de ideas que compartimos y que hemos sido capaces de difundir a lo largo de siglos. El artículo señala, en particular, las similitudes entre el iusnaturalismo de inicios de la Edad Moderna - a través del caso del filósofo español Francisco Suárez-y el iusnaturalismo contemporáneo representado por autores como Ronald Dworkin o John Finnis.

En 2017 se cumplieron cuatrocientos años del fallecimiento de Francisco Suárez (Granada, 1548-Lisboa, 1617), escolástico jesuita y figura prominente del Siglo de Oro español. Animado por esa fecha, quien escribe publicó un libro que conmemora su vida y obra, y que intenta trazar un viaje

* Licenciado en derecho por la UNAM y maestro en derecho por la Universidad Jean Moulin de Lyon, Francia. 
por la Edad Media y los albores de la Edad Moderna. ${ }^{1}$ En él se rechazan las ideas preconcebidas sobre la escolástica y se pretende poner en relieve su originalidad y sus aportaciones: los derechos subjetivos como facultades morales e inherentes al ser humano, los principios como parte de los sistemas jurídicos, la soberanía enraizada en el pueblo y la defensa del derecho de propiedad son apenas algunos ejemplos de las ideas escolásticas que han forjado el pensamiento jurídico moderno.

Si aquel libro tenía por objeto estudiar a Suárez en el contexto de su propia época, el presente artículo busca mostrar —en cambio - las afinidades entre las ideas del escolástico español y las ideas de los pensadores contemporáneos. Un diálogo, pues, entre el pasado y el presente. Por ello, se hará referencia a los contemporáneos, cuando sea necesario, de manera muy puntual, en el entendido de que son - hoy en día - autores conocidos ampliamente por el público académico. En cuanto a las referencias a Francisco Suárez y a la escolástica, éstas serán más detalladas, en tanto que el propósito es subrayar la originalidad de sus aportaciones.

Suárez explica la validez del derecho mediante la teoría aristotélica de las causas: la causa eficiente (la autoridad), la causa formal (el procedimiento formal de creación del derecho), la causa material (la justicia) y la causa final (el bien común). Dicho de otro modo, el derecho es válido porque: a) es creado por una autoridad (lo cual se corresponde con la tesis de John Austin); b) cumple con el procedimiento formal (piénsese en las afirmaciones de Hans Kelsen o H. L. A. Hart); c) es justo, y d) busca el bien común. Las dos primeras causas son claramente defendidas por los pensadores iuspositivistas. El iusnaturalismo, por su parte, reprocha el carácter parcial del iuspositivismo, en la medida en que el iusnaturalismo no limita la validez del derecho a las dos primeras causas, sino que engloba a cuatro de ellas. Por último, Suárez se suma también — como escolástico que es-a la tesis que indica que el derecho está compuesto por principios, a diferencia de los iuspositivistas que, esencialmente, la niegan.

\section{LA ESCOLÁSTICA}

La vida y la obra de Suárez encarnan una transición entre la Edad Media y la Edad Moderna. Suárez, un hombre que perteneció a la tradición escolástica y, por consiguiente, al espíritu medieval, fue sin embargo un hombre moderno

1 Patiño Gutiérrez, Carlos, La validez del derecho en la escolástica. Desobediencia, iusnaturalismo y libre albedrío en Francisco Suárez, México, UNAM, Instituto de Investigaciones Jurídicas, 2017. 
por igual. Sería imposible concebir a la escolástica española fuera de un contexto humanista y renacentista, o despreocupada de los grandes problemas de su tiempo; por el contrario, estuvo muy enraizada en el Siglo de Oro y en el mundo cervantino y, por lo tanto, moderno.

Con la caída del Imperio Romano de Occidente y, en consecuencia, con el fin de la Edad Antigua, la Europa medieval atestiguó la pérdida tanto de la filosofía de la antigua Grecia, como del derecho de la antigua Roma, con excepción de ciertos lugares en los que su estudio no fue interrumpido. Fuera de la cultura europea, sería en los pueblos musulmanes en los que se continuaría leyendo por siglos a los filósofos griegos. De hecho, fue a través de los musulmanes que los europeos recuperarían la filosofía griega durante la Baja Edad Media. Esto tuvo lugar, entre los europeos, en particular hacia el siglo XI, gracias - precisamente - a la escolástica y a hombres como Tomás de Aquino que reintrodujeron a Aristóteles. En cuanto al derecho romano, renació en lo que hoy es Italia, también en el siglo XI, debido a los estudiosos que, como Irnerio, desarrollaron la escolástica jurídica.

La escolástica está vinculada a la recuperación del conocimiento griego y romano. Y no sólo eso: al mismo tiempo, se esforzó en conciliarlo con el cristianismo. La escolástica encarna, pues, esa tradición erudita de recuperación y de conciliación. En crisis hacia el siglo XV, la escolástica halló, por fortuna, un último aliento en España. Por esa razón, se le ha llamado "escolástica tardía", "escolástica segunda" o — simplemente— "escolástica española". Se organizó alrededor de la célebre Escuela de Salamanca, un notable núcleo universitario en el que destacaron figuras como Francisco de Vitoria y Francisco Suárez.

En suma, la escolástica tuvo un periodo de auge durante el siglo XIII, particularmente con Tomás de Aquino, y un periodo de decadencia entre los siglos XIV y XV, el cual fue interrumpido temporalmente por el florecimiento de la escolástica española de los siglos XVI y XVII.

La escolástica española suele asociarse, como se dijo antes, con la Escuela de Salamanca. Sin embargo, se trata esta última de una expresión que, en realidad, engloba a profesores y a universidades de distinta índole. Los jesuitas destacaron, por ejemplo, a través de la Universidad de Alcalá de Henares; los dominicos en la Universidad de Salamanca, y así respectivamente con las distintas órdenes religiosas.

La escolástica, entonces, suele entenderse como una conciliación del legado de la filosofía de la Antigüedad con la fe cristiana. Sin embargo, esta apreciación es algo limitada. Yves Mausen indica que más que una concilia- 
ción, la escolástica es un método racional de explicación y de concordancia de los textos que organiza a toda investigación. ${ }^{2}$

Normalmente se ha puesto énfasis en cómo la escolástica rescató el pensamiento aristotélico (piénsese en la teoría de las causas), para adaptarlo al cristianismo y explicar así, por ejemplo, la existencia de Dios. Pero, en efecto, más que un asunto de conciliación, la escolástica es una cuestión metodológica.

La escolástica se desarrolló a partir del método dialéctico y se basó en el argumento de autoridad. ${ }^{3}$ La dialéctica es un método de distinciones, divisiones y oposiciones. Platón — por ejemplo - plantea que, para llegar al conocimiento, es necesario un ejercicio basado en el diálogo que, a fuerza de ir y venir en la palabra, abre el camino hacia las ideas. En los diálogos de Platón, vemos a Sócrates distinguiendo en todo tiempo una cuestión en dos aspectos y, sucesivamente, dividirlo de nuevo en dos, interpelando, arrojando luz, encontrando contradicciones en el interlocutor, para redirigir el rumbo y desvelar la cuestión abordada. Por ejemplo, en el Banquete divide el amor en una Venus celestial y una carnal, y la última en una erótica y otra reproductiva, y así sucesivamente.

A diferencia de Platón, Aristóteles refutará esta acepción e identificará a la dialéctica como una lógica de lo probable o de la apariencia. La Edad Media identificará, en cambio, la dialéctica con la lógica general, y Hegel hará renacer el término, pero ahora como síntesis de los opuestos. La concepción platónica de la dialéctica hace referencia al poder del diálogo para hallar la verdad, es un camino para ascender, por medio de las divisiones y las oposiciones, pasando por lo múltiple, a las esencias de las cosas.

Se verá, por lo tanto, a los estudiosos medievales, en su afán por el conocimiento, haciendo constantemente distinciones, categorías y definiciones, a la manera de los antiguos.

2 Mausen, Yves, "Scolastique juridique", en Alland, Denis y Rials, Stéphane (eds.), Dictionnaire de culture juridique, París, Quadrige-Lamy-PUF, 2003, p. 1394.

3 En este respecto, son notables los textos tanto de Rolando Tamayo y Salmorán como de Yves Mausen a propósito de esa metodología. Yves Mausen aborda la metodología escolástica de manera breve pero densa en la voz "Scolastique juridique" (véase Mausen, Yves, op. cit., pp. 1394-1398). En cuanto a Rolando Tamayo y Salmorán, consagra un capítulo a la metodología de los glosadores y comentadores, y en otro capítulo muestra esta metodología a través del ejemplo, traducción y comentarios de los textos de Bártolo y Baldo a propósito del derecho natural. Véase Tamayo y Salmorán, Rolando, Los publicistas medievales y la formación de la tradición politica de Occidente, México, UNAM, Instituto de Investigaciones Jurídicas, 2005. En particular, capítulos VI ("El renacimiento de la jurisprudencia") y VIII (“Jurisprudencia medieval y formación de la teoría política"). 
Rolando Tamayo y Salmorán subraya, por otro lado, el papel que jugó el otro elemento esencial de la escolástica: el argumento de autoridad; y, al respecto, señala que el método escolástico:

presupone la autoridad de ciertos libros en tanto que corpus completo y consistente de doctrina. Pero, paradójicamente, este método también supone la existencia de lagunas y contradicciones en el texto. El objetivo fundamental de este método consiste en hacer una summa del texto, integrando las lacunae y resolviendo las contradictiones. El método escolástico, i. e., la dialéctica, logró la conciliación de los opuestos. ${ }^{4}$

Una obra considerada como un corpus consistente de doctrina es, por excelencia, la Biblia. En el terreno jurídico, lo mismo ocurrirá con el Corpus iuris civilis; más aún, igual sucederá con algunas obras producto de la misma escolástica, por ejemplo, la Suma teológica de Tomás de Aquino; es decir, los seguidores de Tomás de Aquino, como Suárez, vieron en la Suma también un "corpus completo y consistente de doctrina".

Las afirmaciones contenidas en estas obras serían tenidas como verdaderas e incuestionables, dogmas que, ante posibles lagunas del propio corpus, obligaron a los escolásticos a realizar ejercicios de gimnasia intelectual para resolver y colmar esos vacíos.

El argumento de autoridad gozará aquí de un lugar privilegiado. Si lo dice la Biblia, la Metafísica, el Digesto o la Suma, se tendrá por cierto; y ahí mismo encontraremos la debilidad y el fundamento de la crítica lanzada en contra de la escolástica. Para los opositores de la escolástica, es un error considerar las premisas de la Biblia o del Digesto como verdades necesarias, y no se equivocan, no hay, en efecto, razón para ello; a menos, que creyéramos que Justiniano recibió el Corpus iuris civilis de manos divinas. Sólo si el Digesto (o la Biblia) hubiese sido escrita realmente por Dios, entonces no dudaríamos la posibilidad de que las premisas son, realmente, verdades necesarias, pero resulta dudoso, por no decir imposible.

De entre los escolásticos, quizás el más importante sea — por la talla de su talento- Tomás de Aquino. Nuestra admiración es confesa, pero también debemos de reconocer algunos reparos. Tomás de Aquino no ingresa en lo desconocido, o dicho de otro modo, no empieza su reflexión con el afán de descubrir un conocimiento; su mecánica es la opuesta, pues al partir de la fe, sabe de antemano lo que quiere concluir. Tiene un ánimo de justificación racional, lo cual contradice la esencia del conocimiento racional

4 Tamayo y Salmorán, Rolando, op. cit., p. 143. 
que él defiende. Pues parte, dígase una vez más, de premisas que se tienen por verdades necesarias. Encontramos en los escolásticos discusiones que, para nuestros ojos modernos, pueden parecer bizantinas. Suárez puede, por ejemplo, partir de alguna referencia a la obra de Tomás de Aquino y después especular que Dios "quiere" esto, pero no "desea" aquello, con fundamento en tal o cual autoridad, y arribar finalmente a una conclusión. ${ }^{5}$

Todas estas críticas en contra de la escolástica están fundadas. Pero es innegable, por otro lado, la solidez intelectual de Tomás de Aquino. Sería un error restar valor a las fuentes de la escolástica (Platón, Aristóteles, Justiniano), por el simple hecho de haber sido consideradas por los escolásticos como verdades necesarias, o más aún, restar importancia a los intérpretes de esas fuentes (es decir, a los propios escolásticos, como Tomás de Aquino). Y sería peor que, por las discusiones bizantinas, se despreciaran otras de sus discusiones, más bien rigurosas y luminosas. El valor de esas aportaciones, específicamente las de Suárez, es lo que se pretende mostrar al lector.

Rolando Tamayo y Salmorán e Yves Mausen describen de manera similar la metodología escolástica que consta de cuatro partes o movimientos. ${ }^{6}$ Tamayo y Salmorán señala que se presenta: 1) la determinación de un caso previsto - por ejemplo - por el Corpus iuris; 2) la selección de textos y la resolución de contradicciones; 3) la obtención de generalizaciones, y 4) la presentación de los problemas que luego serán discutidos. El objetivo, dice Tamayo y Salmorán, es superar los opuestos y las contradicciones, lo cual nos lleva, o regresa, al terreno de la dialéctica. ${ }^{7}$

En cuanto a Yves Mausen, él afirma que el planteamiento escolástico clásico "procede en cuatro movimientos: la presentación y la discusión de los argumentos, y contra argumentos, la solución, la crítica de los argumentos que la contradecían". ${ }^{8}$

La forma en cómo los escolásticos organizan sus textos muestran una estructura intelectual muy concreta y original. En la Suma teológica de Tomás de Aquino, de manera sistemática, encontraremos una misma disposi-

5 Véase Patiño Gutiérrez, Carlos, op. cit., pp. 123-141. En esas páginas, se analizan las Disputaciones metafísicas de Suárez y se muestra esa inclinación por referir lo que Dios quiere, considera o desea.

6 Ambos, Tamayo y Salmorán y Mausen, destacan también el uso sistemático de la distinctio y de la quoestio. Véase Mausen, Yves, op. cit., p. 1396. Y véase Tamayo y Salmorán, Rolando, op. cit., p. 143.

7 Tamayo y Salmorán, Rolando, op. cit., p. 144.

8 Mausen, Yves, op. cit., p. 1395. 
ción, ésta se divide en tres partes. ${ }^{9}$ Cada parte se subdivide en cuestiones y éstas en artículos; ${ }^{10}$ cada artículo está integrado por cuatro elementos: 1) el planteamiento del problema ("Utrum...", "Si...", por ejemplo, "Si Dios existe"); 2) la disputa o presentación dialéctica de los argumentos, primero los que están en contra de la tesis que Tomás de Aquino afirmará ("Videtur...", "Parece que...", "Parece que Dios no existe")11 y luego los argumentos a favor tomados de alguna autoridad ("Sed contra...", "Por el contrario..."); 3) el cuerpo del artículo que es la respuesta en sí misma que da Tomás de Aquino ("Respondeo..." "Respondo que..."); y 4) la réplica a cada uno de los argumentos que se señalaron en contra (la respuesta al Videtur antes mencionado). ${ }^{12} \mathrm{Al}$ citar la Suma, tradicionalmente se señala la parte, la cuestión y el artículo; por ejemplo, la célebre reflexión de Tomás de Aquino a propósito de la duda de "Si Dios existe o no", se encuentra en la primera parte de la Suma, en la cuestión segunda, artículo tres (es decir, $S$. t., Ia, 2, 3), y sobre la cual el lector encontrará a pie de página lo que el dominico dice al respecto (en palabras resumidas) como un ejemplo de la metodología escolástica. ${ }^{13}$

9 Curiosamente, la segunda parte, en particular, se compone a su vez de dos partes: la prima secundae (primera parte de la segunda parte) y la secunda secundae (segunda parte de la segunda parte), se suelen citar, respectivamente, de este modo: "Ia, IIae" y "IIa, IIae".

10 Citaremos la Suma Teológica en la forma convencional, es decir: parte, cuestión, artículo, etc. Por ejemplo, la primera parte de la segunda parte, cuestión 90, artículo 3o., se expresa del siguiente modo con $S$. $t$., Ia, IIae, 90, 3.

11 En algunas traducciones va precedida por la palabra "objeciones" o "dificultades", agregada por el editor o traductor.

12 En algunas traducciones va precedida por las palabras "respuesta a las objeciones" o "soluciones", agregadas por el editor o traductor. Cada réplica inicia con " $A d$..." (" $A d$ primum...", es decir, "Al primer argumento hay que decir que..."); por ello, para las citas, las referencias a estas réplicas suelen hacerse con la abreviatura " $a d$ ” y el número correspondiente. Por ejemplo, S. t. Ia, IIae, 90, 3, ad 2 (Es la primera parte de la segunda parte de la Suma Teológica, cuestión 90, artículo 3o., ad secundum, es decir, la respuesta 2 [dicho de otro modo, la réplica a la objeción planteada en el Videtur segundo]).

13 Parece que Dios no existe pues todo lo que existe en el mundo encuentra su ser en otros principios, y suponiendo que Dios no existe, lo que es natural encuentra su principio en la naturaleza, mientras que lo que es intencionado se encuentra en la voluntad humana, así pues, no hay necesidad alguna de acudir a la existencia de Dios. Por el contrario, está lo que se dice en la persona de Dios: 'Yo soy el que soy' (Éxodo, 3, 14). Respondo que la existencia de Dios se puede probar de cinco maneras distintas: 1) Todo lo que se mueve necesita ser movido por algo más, éste por aquél, y aquél, a su vez, por otro, pero este proceder no se puede llevar indefinidamente, porque no se llegaría al primero que mueve, y así no habría motor alguno, pues los motores intermedios no mueven más que por el primer motor; por lo tanto, es necesario llegar a aquel primer motor al que nadie mueve; en éste, todos reconocen 
Si bien hemos hablado de la escolástica general, también podríamos hablar ahora de la existencia, en lo particular, de una escolástica "jurídica". Yves Mausen afirma que si, en principio, optamos por entender a la escolástica como ejercicio de conciliación, entonces estaremos haciendo referencia a aquellos pensadores medievales que recuperaron las obras filosóficas para armonizarlas con la teología cristiana. En este mismo sentido, señala Mausen, la escolástica "jurídica" comprendería, por su parte, la labor de los juristas medievales que rescataron el derecho romano para armonizarlo con el mundo que les tocó vivir. Esos juristas medievales son los que hoy conocemos como los glosadores y los comentadores. ${ }^{14}$

$\mathrm{Si}$, en cambio, entendemos la escolástica como una metodología, entonces la escolástica jurídica igualmente se puede concebir como la metodología aplicada a la interpretación de las fuentes jurídicas. Más que una conciliación, los textos de Suárez dan muestra de un verdadero ejercicio metodológico, como el que hemos descrito, y cuyas reflexiones quisiéramos compartir aquí.

a Dios. 2) Encontramos que en el mundo sensible hay un orden de causas eficientes. En las causas eficientes no es posible proceder indefinidamente, pues en todas las causas eficientes hay orden: la primera es causa de la intermedia; y ésta, sea una o múltiple, lo es de la última. Si se quita la causa, desaparece el efecto, si en el orden de las causas eficientes no existiera la primera, no se daría tampoco ni la última ni la intermedia. Es necesario admitir una causa eficiente primera, todos la llaman Dios. 3) Encontramos que las cosas pueden existir o no existir, si todas las cosas llevan en sí mismas la posibilidad de no existir, hubo un tiempo en que nada existió, pero si esto es verdad, tampoco ahora existiría nada, puesto que lo que no existe no empieza a existir más que por algo que ya existe; si nada existía, es imposible que algo empezara a existir. Luego es preciso algún ser necesario cuya causa de su necesidad no esté en otro, sino que él sea causa de la necesidad de los demás, todos le dicen Dios. 4) Encontramos que la bondad, la veracidad, la nobleza y otros valores se dan en las cosas. Hay algo, por tanto, que es muy veraz, muy bueno, muy noble, y en consecuencia es el máximo ser, pues las cosas que son sumamente verdaderas, son seres máximos, así como el fuego, que es el máximo calor, es causa de todos los calores, del mismo modo hay algo que en todos los seres es causa de su existir, de su bondad, de cualquier otra perfección, le llamamos Dios. 5) Todos los cuerpos naturales están en movimiento y tienen un fin preciso; sin embargo, estos cuerpos carecen de inteligencia, y el dirigirse hacia un fin es propio de la inteligencia, por lo tanto, existe un ser inteligente que guía a todos los cuerpos naturales hacia su fin, como la flecha guiada por el arquero, le llamamos Dios. A la objeción, hay que decir que dado que la naturaleza obra por un determinado fin a partir de la dirección de alguien superior, es preciso que todo sea reducido a algún primer principio inmutable y absolutamente necesario, tal como ha sido demostrado (Véase Tomás de Aquino, S. t., Ia, 2, 3).

14 Mausen, Yves, op. cit., pp. 1394-1398. 
Esta revista forma parte del acervo de la Biblioteca Jurídica Virtual del Instituto de Investigaciones Jurídicas de la UNAM

\section{UN COMENTARIO MARGINAL}

Las aportaciones de la escolástica española son bien conocidas. Incluso es un lugar común la naturalidad con la que le concedemos a los escolásticos el crédito por tales contribuciones. Pero pocas veces nos detenemos para constatarlas de primera mano. Las razones son obvias: para el lector de hoy, hay poco interés en ello; los textos suelen ser oscuros, difíciles, y por lo tanto, parecen estar reservados a los especialistas; aunque por otra parte, sorprende - hay que reconocerlo - que su lenguaje y sus temas sean, por momentos, muy actuales todavía.

Hablar de la escolástica supone tratar una serie de temas vinculados a los asuntos que se analizan en este artículo, pero que no es posible abordar aquí (y que me gustaría al menos mencionar): el espíritu de la Edad Media, las implicaciones que tuvo el surgimiento de la Edad Moderna, el descubrimiento de América, el Siglo de Oro y el barroco, el esfuerzo de los moralistas de aquella época por encontrar en la razón la respuesta a qué es el bien y la verdad en la moral, todo ello, como parte del contexto en que se desarrolló la escolástica española. ${ }^{15}$

La obra de los escolásticos suele clasificarse en lectio y relectio. La importancia de las lecciones y relecciones fue doble: en primer lugar, fue el modelo del quehacer pedagógico de los escolásticos, en tanto que profesores, y en segundo lugar, fue la vía por la cual muchos de ellos dejaron constancia de su labor académica: a través de sus alumnos. ${ }^{16}$ En el caso, por

15 Sobre el espíritu de la Edad Media y de la Edad Moderna, véase Patiño Gutiérrez, Carlos, op. cit., pp. 21-42 (es decir, los apartados A. "La Europa premoderna y moderna" y B. "Don Quijote moderno"). Sobre el descubrimiento de América, véase, ibidem, pp. 54-56 (apartado A. "El suceso: el encuentro entre dos mundos y su base jurídica"). Sobre el Siglo de Oro y el barroco español; véase, ibidem, pp. 113-121 (apartado B. "La libertad como fundamento de la moral"). Sobre cómo el bien y la verdad en la moral pueden ser identificadas con la razón; así como, la descripción tomista de la naturaleza libre del ser humano y la estructura moral de los actos de este último; véase, ibidem, pp. 107-113 (apartado A. "Acto humano y ética del derecho en Tomás de Aquino”). Sobre las explicaciones de Suárez a propósito de la naturaleza del libre albedrío y sus conflictos con las predeterminaciones divinas, véase ibidem, pp. 123-141 (apartado A. "El libre albedrío en las Disputaciones metafísicas").

16 La lectio es la lección ordinaria y designa el texto (por ejemplo, la Biblia) que el profesor debía "leer", enseñar y comentar; más tarde la "lectura", es decir la lectio, se convirtió en el comentario en sí mismo, hecho en forma oral, por el profesor en clase. Un ejemplo de una lectura de Vitoria es La ley (la cual consiste en un comentario al "Tratado de la ley" de Tomás de Aquino contenido en la Suma Teológica). La relectio es, en cambio, la cátedra de carácter excepcional, una conferencia magistral, celebrada en los días de fiesta, abierta a todo el público universitario y que se ocupaba principalmente de los temas de actualidad. 
ejemplo, de Francisco de Vitoria, la publicación de su legado intelectual fue posible gracias a las notas tomadas por sus estudiantes de sus lecciones y relecciones. La escolástica, de hecho, se revitalizó en España a partir del momento en que Vitoria introdujo el estudio de la Suma Teológica de Tomás de Aquino (sustituyendo las Sentencias de Pedro Lombardo) en el seno de la Universidad de Salamanca. ${ }^{17}$

Suárez — a diferencia de Vitoria — afortunadamente sí logró publicar sus obras él mismo. Se pueden distinguir dos tipos de obras en Francisco Suárez, las escritas por encargo y las escritas más bien por un interés académico-personal. Como ejemplos de los textos por encargo, podemos mencionar el Defensio fidei, mientras que entre los textos académicos (más sistematizados), encontramos su De legibus y sus Disputationes metaphysicae.

Para situar cronológicamente las obras más destacadas de Suárez, publicadas en vida, habría que comenzar por señalar De verbo incarnato, de 1590, y De mysteriis vitae Christi, de 1592, en Alcalá, España. Ambas son comentarios a la tercera parte de la Suma Teológica de Tomás de Aquino. Entre otras obras ampliamente reconocidas, publicó, en 1597, las ya referidas Disputationes metaphysicae. También destacan, igualmente ya mencionados, el De legibus en 1612 y el Defensio fidei en 1613, publicados en Coimbra. Así pues, desarrolló una obra de una índole muy diversa: teológica, jurídica y filosófica, y que en muchos casos reflejó el rumbó que tomaban sus clases.

En 1597, Suárez fue enviado por el rey Felipe II a Coimbra, en Portugal, y permaneció allí hasta 1615. Durante estos años en Coimbra, publicó su De legibus y su Defensio fidei. Este último período se corresponde también a la controversia surgida entre la Iglesia Católica y el rey protestante de Inglaterra, Jacobo I, en la que Suárez habría de tomar parte. Jacobo I obligó a sus súbditos a hacer un juramento de lealtad de tal modo que excluiría la intervención del papa en la consciencia de los ingleses. Suárez participó en la disputa, a instancias del papa y del rey de España, y escribió, a solicitud

Estas relectiones hicieron muy popular a Vitoria, y entre ellas destacan sobre el poder civil, sobre los indios y sobre el derecho de guerra, en las que abordó los derechos de los indígenas americanos, los excesos de los conquistadores españoles, la guerra justa y el papel del derecho internacional.

17 Frayle Delgado, Luis, "Estudio preliminar", en Vitoria, Francisco de, La ley, Madrid, Tecnos, 2009, p. XIII. 
de ellos, el Defensio fidei ${ }^{18}$ que se oponía a la teoría del derecho de los reyes a gobernar por mandato directo divino. ${ }^{19}$

El De legibus se compone de diez extensísimos libros. Sólo se señalarán, en este caso, los tres primeros libros. El libro I es una introducción a la naturaleza de la ley; el libro II trata de la ley eterna, la ley natural y el derecho de gentes (es aquí donde Suárez hizo su principal contribución al derecho natural y al derecho internacional), el libro III es sobre la ley humana, y es el más interesante en lo que respecta al tema de la validez del derecho.

Ante una ley inválida ¿cabe la desobediencia del derecho? Si en el De legibus se plantea el problema de la validez del derecho, en el Defensio fidei se desarrolla el derecho de resistirlo. Suárez incluso postula la resistencia como un derecho natural, y como moralista que es, nuestro escolástico vincula al derecho con la moral y, a ésta, a su vez, con el libre albedrío; de hecho, Suárez sostiene que: "El fundamento de todo el orden moral es la libertad". ${ }^{20}$ En este sentido, las Disputaciones metafisicas (disputaciones XIX a XXII) abordan amplia y eruditamente la existencia y los problemas del libre albedrío, así como — bien advierte Francisco León Florido- el debate de la libertad en relación con los órdenes causales. ${ }^{21}$ Es decir, el conflicto entre la predeterminación divina y el libre albedrío. Y son precisamente las Disputaciones metafísicas las que mejor reflejan la estructura de la metodología escolástica que hemos explicado antes.

Propongo al lector hacer, a continuación, un breve repaso de las discusiones contemporáneas del derecho para, de ese modo, contrastarlas con las contribuciones escolásticas y, en particular, con las suarecianas.

\section{LA DISCUSIÓN CONTEMPORÁNEA}

Las diferentes concepciones filosóficas que tenemos sobre el derecho se traducen en interpretaciones y prácticas distintas del mismo. Creo que la práctica del derecho — por ejemplo, la labor que realizan los jueces — puede ser objetivista y principalista (como lo propugna el iusnaturalismo), por oposi-

18 Defensa de la fe católica y apostólica contra los errores de la secta anglicana con respuesta a la apología del juramento de lealtad y a la carta dirigida a los príncipes cristianos por el serenísimo Jacobo, rey de Inglaterra.

19 Gómez Robledo, Antonio, Fundadores del derecho internacional (Vitoria, Gentili, Suárez, Grocio), México, UNAM, Instituto de Investigaciones Jurídicas, 1989, pp. 61-63.

20 Suárez, Francisco, Disputaciones metafísicas, Madrid, Tecnos, 2011, p. 199 (XIX, $\mathrm{V}, 21)$.

21 León Florido, Francisco, "Estudio preliminar", en ibidem, p. 49. 
ción a una concepción subjetivista, territorial, normativista y formalista (que defiende el iuspositivismo). Si la filosofía del derecho no es un reflejo de la práctica del derecho, ¿de qué sirve entonces hacer filosofía jurídica? ¿Son acaso meras elucubraciones de filósofos desconectados de la realidad? No lo creo así, por el contrario, la práctica del derecho está determinada por nuestras figuraciones de lo que es el derecho: a veces se trata de una práctica derivada de concepciones muy elaboradas, otras no, algunas muy conscientes y otras casi inadvertidas, y viceversa, las figuraciones están determinadas por la práctica jurídica. ${ }^{22}$ Así, las corrientes filosóficas del derecho, en última instancia, no son sino interpretaciones de lo que es ese fenómeno social que denominamos derecho; interpretaciones que se traducen en tesis a menudo opuestas entre sí.

De acuerdo con el iuspositivismo, el derecho debe ser estudiado por lo que "positivamente" es (por lo que de hecho es), no por lo que debería ser, ni por lo justo o injusto que pueda ser; para John Austin la ley es aquella que es impuesta por una autoridad soberana, independientemente de las estimaciones morales, ${ }^{23}$ y la impone porque tiene el poder para ello. "Indudablemente, cuando Bentham y Austin insistían en distinguir entre el derecho tal cual es y el derecho como debe ser, [...] tenían interés en razonar que tales leyes, aunque afrentasen a la moral, seguían siendo leyes", como dice H. L. A. Hart. ${ }^{24} \mathrm{O}$ como señala la Stanford Encyclopedia of Philosophy:

El positivismo jurídico es la tesis que sostiene que la existencia y el contenido del derecho dependen de hechos sociales y no de sus méritos. El jurista inglés, John Austin (1790-1859), lo formuló así: "La existencia del derecho es una cosa; sus méritos y deméritos son otra [...]”. La tesis positivista no señala que los méritos del derecho sean ininteligibles, intrascendentes o accesorios a la filosofía del derecho. Sostiene que no determinan si las leyes o un sistema jurídico existe o no. Si una sociedad tiene un sistema legal, ello depende de

22 Dworkin ha señalado cómo los jueces incluso abordan, en sus resoluciones, asuntos claramente filosóficos y morales. Los jueces, dice Dworkin, "pueden ser de algún modo filósofos y, de hecho, estudian cuestiones que son objeto de hondas confrontaciones filosóficas"; véase, Dworkin, Ronald, “¿Deben nuestros jueces ser filósofos? ¿Pueden ser filósofos?”, Isonomía, México, núm. 32, abril de 2010, pp. 7-29.

23 Austin, John, The province of jurisprudence determined, Londres, John Murray, 1832, p. XVII.

24 Hart, H. L. A., "El positivismo y la independencia entre el derecho y la moral”, en Dworkin, Ronald, La filosofía del derecho, trad. de Javier Sáinz de los Terreros, 2a. ed., México, Fondo de Cultura Económica, 2014, p. 67. 
la presencia de ciertas estructuras de gobierno, y no de si satisface ideales de justicia, democracia o del Estado de derecho. ${ }^{25}$

Dworkin refuta esta postura del siguiente modo. Para Austin - explica Dworkin - una obligación no es sino una subordinación a una norma; una norma no es sino un mandato; y un mandato no es sino la expresión de una pretensión de que otras personas se comporten de una manera específica, respaldada por la amenaza de la coacción. Austin reconoce diferentes tipos de normas en función del autor del mandato (normas jurídicas, morales o religiosas; si el autor es un sacerdote, se trata de una norma religiosa, por ejemplo). En una comunidad política, hay un poder soberano al que las personas obedecen, las normas jurídicas son, por lo tanto, mandatos de un poder soberano. ${ }^{26}$

"El modelo de Austin", dice Dworkin, "es realmente bello por su simplicidad. En él se afirma el primer dogma del positivismo - que el derecho consiste en una serie de normas especialmente elegidas para regular el orden público - y se ofrece un sencillo criterio fáctico — ¿qué ha mandado el soberano? - como el único necesario para identificar esas normas especiales". ${ }^{27}$ Sin embargo, según observa Dworkin, esta hipótesis iuspositivista no se corresponde con las nociones de autoridad y de sociedad en sus acepciones modernas.

La obediencia no se reduce, entonces, al mero argumento de la fuerza o de la amenaza de castigo; de acuerdo con Dworkin:

la hipótesis clave de Austin, de que en toda comunidad puede encontrarse un determinado grupo o institución que domina en última instancia a todos los demás grupos, no parece valedera en la sociedad compleja. El mando político, en una nación moderna, es pluralista y versátil, es materia de moderación, compromiso, cooperación y alianza, de modo que resulta a menudo imposible indicar una persona o un grupo que ostente ese espectacular dominio que haría falta para calificarle de soberano con arreglo a la tesis de Austin. ${ }^{28}$

25 Green, Leslie, "Legal Positivism", en Zalta, Edward N., The Stanford Encyclopedia of Philosophy, Stanford, Universidad de Stanford, edición de otoño de 2009, http://plato. stanford.edu/entries/legal-positivism/ (consultado el 20 de septiembre de 2017).

26 Dworkin, Ronald, “¿Es el derecho un sistema de normas?”, en id. (comp.), La filosofia del derecho, trad. de Javier Sáinz de los Terreros, 2a. ed., México, Fondo de Cultura Económica, 2014, p. 109.

27 Ibidem, p. 110.

28 Idem. 
Además, el esquema trazado por Austin — dice Dworkin - no distingue entre tipos de mandatos; por ejemplo, no hace una diferencia entre los mandatos dictados por una autoridad y por un criminal. Ambos pueden lograr la sujeción mediante amenazas de coacción..$^{29}$ Pero no podemos equipararlos. Los mandatos de un criminal — que las víctimas obedecen por coacciónno constituyen normas jurídicas.

La versión que, en cambio, ofrece Hart del iuspositivismo — señala Dworkin- es más interesante: distingue dos clases de normas, por una parte, normas primarias (que otorgan derechos e imponen obligaciones) y, por otra parte, normas secundarias (que regulan los procedimientos de creación, modificación y extinción de normas primarias); ${ }^{30}$ por ejemplo, las disposiciones que regulan los alimentos en el código civil son normas primarias; los artículos 71 y 72 de la Constitución son normas secundarias.

Así, la validez de las normas no está supeditada, por lo tanto, a la fuerza física de sus autores, para Hart, la validez puede tener dos fuentes: la aceptación de la norma (es decir, una regla tenida como patrón de conducta que requiere, además, su consideración como obligatoria); o bien, una norma puede ser obligatoria si es creada de conformidad con una norma secundaria. " "Una norma no será jamás obligatoria por el solo hecho de que una persona dotada de poder material así lo desee; esa persona ha de tener autoridad para emitirla o no habrá tal norma, y dicha autoridad sólo puede provenir de otra norma que obligue ya a las personas a quienes se dirige", apunta Dworkin. ${ }^{32} \mathrm{He}$ aquí pues el segundo postulado del iuspositivismo: para que una norma sea válida, no sólo debe ser creada por un autoridad, sino de conformidad con un procedimiento preestablecido.

Dworkin critica este carácter estrictamente normativista que sugiere el iuspositivismo (es decir, normas cuya validez se explica a partir de otras normas o a partir de la coacción). Y advierte la existencia de "principios": normas o pautas extrajurídicas, esto es, normas de carácter moral dentro del sistema jurídico. El iuspositivismo admite la posibilidad de hacer valoraciones morales a propósito del derecho, pero estima que la moralidad o inmoralidad de las normas no afecta su validez. Se trata pues de un escepticismo moral, o dicho de otro modo, de una irrelevancia moral, o de una amoralidad, al menos en lo que respecta a la validez jurídica. Pero Dworkin

\footnotetext{
29 Ibidem, p. 111.

30 Idem.

31 Ibidem, p. 113.

32 Idem.
} 
plantea lo contrario: no sólo sostiene la posibilidad de hacer valoraciones morales sobre el derecho, sino que sostiene la existencia de elementos morales en el derecho que lo definen y determinan.

"Denomino 'principio' a una norma que es menester observar", dice Dworkin, "no porque haga posible o asegure una situación económica, política o social que se juzgue conveniente, sino por ser un imperativo de justicia, de honestidad o de alguna dimensión de la moral". ${ }^{33}$ Dworkin, incluso, muestra la existencia de principios en el derecho a partir de algunos casos judiciales. ${ }^{34}$

Los sistemas jurídicos están compuestos por normas (en sentido amplio). A su vez, estas normas se dividen en normas (en sentido estricto) y reglas (disposiciones jurídicas ordinarias). Las normas, en sentido estricto, se pueden identificar con los principios, entendidos éstos ya sea como criterios de optimización o simplemente como criterios morales. Y como señala Dworkin, nuestros sistemas jurídicos están repletos de criterios de optimización o de criterios morales. ${ }^{35}$ Así ocurre con los principios consagrados en nuestra

33 Ibidem, p. 118.

34 En la práctica del derecho aludimos en numerosas ocasiones a normas de carácter moral. A veces, y por fortuna, los jueces resuelven apelando a principios de carácter moral y contraviniendo lo establecido por las normas jurídicas o colmando vacíos por un imperativo de justicia. Así lo ilustra Dworkin con el caso Henningsen vs. Bloomfields Motors, Inc. y con el caso Riggs vs. Palmer. En el primer caso, Henningsen compró un automóvil y firmó un contrato establecido por el fabricante por medio del cual este último limitaba su responsabilidad a la reparación de piezas defectuosas, deslindándose de otras responsabilidades (gastos médicos derivados de un accidente, etcétera). Surgido el conflicto, el juez terminó por conceder la razón a Henningsen: más allá de la libertad de contratación, esgrimió un argumento que se resumiría en la injusticia y el ánimo de una de las partes en obtener un provecho ilegítimo. En el segundo caso, un heredero, instituido en el testamento de su abuelo, decidió privar de la vida a este último para recibir la herencia; en contra de las disposiciones legales, el juez negó conceder la herencia haciendo alusión a principios tales como: "Nadie tiene derecho a aprovecharse de su propio fraude, o sacar provecho de su delito, o a fundar una demanda en su propia iniquidad, o a adquirir la propiedad a consecuencia de su crimen". Ibidem, pp. 119-121. En ambos casos, se trata o bien de razones morales o bien de principios. "Tan pronto como identificamos los principios del derecho como un orden peculiar de normas, diferente de las normas jurídicas", señala Dworkin, “descubrimos súbitamente su presencia en nuestro entorno. Los profesores de derecho los enseñan, los textos jurídicos los citan, los historiadores del derecho los celebran; pero estos principios parecen funcionar de modo más enérgico, revestir más importancia, en casos difíciles como las causas de Riggs y Henningsen". Ibidem, p. 129.

35 Para Dworkin, un criterio de optimización es: "una meta que ha de alcanzarse para el perfeccionamiento de algún aspecto económico, político o social de la colectividad", ibidem, p. 118. Puede encontrarse una definición similar en Bernal Pulido, Carlos, "Estructura y límites de la ponderación", Doxa. Cuadernos de Filosofía del Derecho, Universidad de 
Constitución, tales como ciertos valores morales (la vida o la dignidad) o ciertos criterios de optimización (la democracia, por ejemplo, es considerada, por el artículo 3o., como "un sistema de vida fundado en el constante mejoramiento económico, social y cultural del pueblo"; o bien, otro criterio de optimización es, por ejemplo, el principio de interés superior de la niñez, entendido como una directriz o instrucción de cómo debe hacerse algo en la mayor medida posible). En efecto, apenas descubrimos los principios, como indica Dworkin, los vemos surgir por doquier.

Y para cerrar este punto sobre la vinculación entre el derecho y la moral, baste recordar también que John Finnis concede, por su parte, al bien común un rol muy importante cuando explica nuestra obligación de obedecer el derecho. La sorpresa que Finnis provoca en los lectores, por su énfasis en el bien común, se disipa tan pronto como se considera el hecho de que él es -al igual que Suárez- un tomista y, por lo tanto, inevitablemente aristotélico. Dedica, a lo largo de su obra Ley natural y derechos naturales, innumerables reflexiones sobre el bien común, en particular, en el capítulo seis, apartado ocho. ${ }^{36}$

\section{LAS CONTRIBUCIONES SUARECIANAS}

Las causas aristotélicas son fundamentales para comprender - desde un punto de vista teológico - el ser y devenir de las cosas y, en general, el acto mismo de creación del universo. Para la escolástica, durante la creación hubo un primer movimiento expansivo, desencadenado por Dios mismo, a manera de una explosión. Posteriormente, Dios es también autor de un segundo movimiento, por el cual las criaturas regresan a él, se trata de una suerte de implosión.

Tomás de Aquino desarrolló su teoría del derecho desde una perspectiva teológica doble. En una relación de causalidad, Dios es el principio de todas las criaturas. En cambio, en una relación de finalidad, todas ellas son posteriormente dirigidas hacia él, pues todo regresa siempre a Dios. Él es, pues, el principio (causa eficiente) y destino (causa final). Y el hombre, dotado - a diferencia de las otras criaturas - de libre albedrío, debe conducir

Alicante, núm. 26, 2003, pp. 25 y 26. Véase también Alexy, Robert, Teoría de los derechos fundamentales, trad. de Ernesto Garzón Valdés, Madrid, Centro de Estudios Políticos y Constitucionales, 1997.

36 Finnis, John, Ley natural y derechos naturales, trad. de Cristóbal Orrego Sánchez, Buenos Aires, Abeledo-Perrot, 2000, pp. 183-185. 
todas sus acciones a ese fin. Y, para ello, la ley es su medio. Por lo tanto, "la ley responde así a un profundo imperativo ético [...] como pedagoga que encauza al hombre hacia su término". ${ }^{37}$

Suárez explica el ser (o la validez) del derecho a partir — como es natural- de la concepción escolástica de la ley. Se apega a las causas de la ley, señaladas por Tomás de Aquino (quien a su vez las retomó de la teoría de las causas de Aristóteles), es decir, la causa eficiente, la causa material, la causa formal y la causa final. ${ }^{38}$

"Para Aristóteles", señala Francisco Larroyo, "todas las cosas se encuentran en constante cambio. Los seres que hoy envejecen antes nacieron y se desarrollaron; los que hoy nacen, indefectiblemente morirán". ${ }^{39}$ Dos palabras nos ayudan a comprender estas transformaciones: potencia y acto; y Francisco Larroyo las ilustra diciendo que, por ejemplo, "un huevo se convierte en polluelo y este se convertirá en gallo: por lo tanto, el polluelo se encuentra en acto, respecto del huevo, y en potencia respecto del gallo". Larroyo dice que: "por esta vía resuelve Aristóteles el problema capital de la filosofía teorética de los griegos: concebir en tal forma el ser que sea posible explicar por éste el devenir". ${ }^{40}$

El polluelo es un gallo en potencia y esa potencia se transforma en acto por las cuatro causas ya mencionadas: la causa eficiente, la causa material, la causa formal y la causa final. Larroyo pone el ejemplo de una escultura: una escultura es una escultura, pero antes no lo era. La causa material es aquello de lo cual algo nace (el material, en este caso el mármol); la causa formal es la idea de escultura (la forma presente en la mente del artista que la esculpirá); la causa eficiente es el principio del cambio o del movimiento (el escultor que labra a golpes la piedra); la causa final es el fin al que se dirige la escultura (la belleza). ${ }^{41}$

En este afán de explicar cómo las cosas llegan a ser lo que son, Suárez indica que la causa eficiente de la ley humana (derecho positivo) es la autoridad "ya que la ley debe ser dada por alguien que tiene el poder y la

37 Aubert, Jean-Marie, "La pédagogie divine par la loi [introducción y notas]", en Tomás de Aquino, Somme théologique, París, Éditions du Cerf, 1997, t. II, p. 568.

38 Suárez, Francisco, De legibus, I, 13, 1.

39 Larroyo, Francisco, "Estudio introductorio", en Aristóteles, Metafísica, México, Porrúa, 1987, p. LV.

40 Idem.

41 Idem. 
jurisdicción". ${ }^{42}$ La causa formal, por su parte, es la forma en que la ley, dice Suárez, debe crearse..$^{43}$

El iuspositivismo limita los criterios de validez a estas dos primeras condiciones. Son dos criterios que, por cierto - como veremos unos renglones más abajo-, el iusnaturalismo no niega (ni el mismo Suárez; por el contrario, él mismo los enuncia y exige). Podemos decir, por lo tanto, que el iuspositivismo reduce el derecho a su forma y no considera otros criterios de validez del derecho. Suárez — en cambio - reconoce los criterios iuspositivistas como necesarios, pero no suficientes.

Los otros criterios de validez son de carácter moral; y precisamente son éstos los que causan resquemor en el espíritu iuspositivista: la causa material es la justicia porque la ley, dice Suárez, "debe consistir de una cosa honesta", ${ }^{44} \mathrm{y}$, por último, la causa final es el bien común, porque "la ley debe ser creada para el bien común". ${ }^{45}$ Una ley que no incluya estos criterios, en realidad, no es una ley, y de ello se deduce que no es obligatoria. De hecho, Suárez dice: "Cada ley humana obliga a todas las personas que son miembros de la comunidad para la cual fue creada la ley si todas las demás condiciones se cumplen. Digo esto porque en la ley deben cumplirse con todas las demás condiciones para que la ley obligue". ${ }^{46}$

Ahora veamos con más detalle lo que Suárez indica sobre estas cuatro condiciones de validez. De acuerdo con Suárez, la sociedad requiere de una autoridad. El poder - afirma - reside en el pueblo y la prerrogativa esencial de este poder es la facultad de legislar. ${ }^{47}$ Suárez dice, a propósito de esta facultad, que: "no reside en ningún hombre en particular, sino en el conjunto de todos los hombres. Esta tesis es general y verdadera. Se encuentra en Tomás de Aquino quien considera que el príncipe tiene el poder de hacer leyes y que este poder le fue transmitido por la comunidad. Esto es lo que las leyes civiles afirman y proclaman". ${ }^{48}$

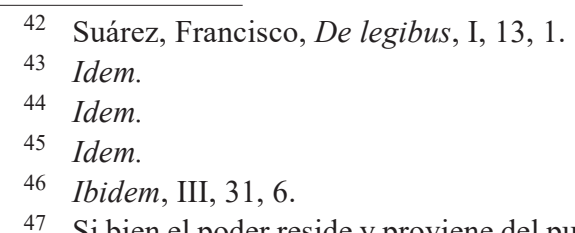

47 Si bien el poder reside y proviene del pueblo, Suárez sostiene que dicho poder popular se originó y fue transmitido, en última instancia, por Dios. Es decir, si la autoridad tiene poder es porque lo recibió del pueblo; y éste, a su vez, de Dios. Así, el poder y la prerrogativa de dictar la ley humana deriva de una ley superior, pero - dice Suárez - la consumación de la forma de gobierno, en cada caso particular, es de derecho positivo, esto es, los hombres pueden, por lo tanto, elegir cualquier forma de gobierno, Véase ibidem, III, 4, 1.

48 Ibidem, III, 2, 3. 
Este poder compartido es posible — señala Suárez - por la obvia razón de que los hombres nacen libres por naturaleza; por lo tanto, nadie tiene ni la jurisdicción ni el dominio sobre los otros. ${ }^{49} \mathrm{~A}$ la libertad, Suárez añade la igualdad natural de los hombres. De acuerdo con él, los hombres "no son superiores a los demás, ni por naturaleza algunos poseen este poder más que otros". ${ }^{50}$

Sin embargo, que seamos libres e iguales por naturaleza no significa que podamos prescindir de la autoridad ni de la subordinación a la organización social y política. Suárez explica el origen de la sociedad indicando que la multitud humana "se reúne en un cuerpo político con un vínculo social para ayudarse mutuamente de cara a un fin político". ${ }^{51}$ En el marco de la igualdad y la libertad naturales, la creación de la sociedad implica la sujeción de los hombres al poder transmitido para que la sociedad logre funcionar..$^{52}$ Así, los hombres no pueden, al mismo tiempo, organizarse y no vincularse a la organización. ${ }^{53}$

Para Suárez, la obediencia a la autoridad es una obligación, desde el momento en que la sociedad es creada, no es potestad de los hombres decidir integrarse o no a ella ni aceptar o no su poder. ${ }^{54}$ Suárez también señala que "la sola justicia de la acción prevista por la ley no es suficiente para que sea obligatoria", ${ }^{55}$ según él, ni la simple justicia ni la participación de los consejeros del príncipe son suficientes; es necesario que la ley sea creada por la autoridad, la ley estaría incompleta, dice, "si carece de la voluntad de aquel que tiene el poder; el poder y la voluntad de los cuales la ley recibe su fuerza y su ser". 56

En suma, la mera justicia de la ley no basta, ésta se debe dictar por una autoridad y sin dejar de respetar las formas previstas para su creación. A

\footnotetext{
49 Idem.

50 Ibidem, III, $2,1$.

51 Ibidem, III, 2, 4.
}

52 Al respecto, Suárez menciona que: "No cualquier hombre puede dirigir a otro, de la misma manera que un igual no puede obligar a otro igual; es obvio porque no hay ninguna razón por la que uno esté obligado obedecer al otro, ni que éste obedezca a aquél. De otro modo, la guerra podría ser justa para ambas partes. Por lo tanto, es necesario un poder especial y superior para obligar válida y efectivamente". Ibidem, I, 8, 3 .

53 "En consecuencia [dice Suárez] si imaginamos que los hombres quieren estas dos cosas, es decir, reunirse de esta manera, pero bajo la condición de no estar sometidos, esta actitud sería contradictoria y no podrían hacer nada". Ibidem, III, 2, 4.

\footnotetext{
54 Idem.

55 Ibidem, I, 8, 10.

56 Idem.
} 
pesar de lo anterior, la justicia o injusticia de la ley no es un asunto menor: debe ser considerada de igual modo como una condición de la ley. Pues sólo puede llamarse ley a "la regla recta y honesta". ${ }^{57}$ Suárez indica que, según Isidoro de Sevilla, "la ley debe ser honesta y justa". ${ }^{58}$ Así, la ley injusta "no es una ley", dice Suárez, "sino que recibe el nombre de ley sólo por analogía, porque prescribe una determinada conducta". ${ }^{59}$ De este modo, las disposiciones humanas pueden ser justas o injustas, pero sólo las leyes justas son verdaderas leyes y sólo ellas obligan a los hombres. ${ }^{60}$

También es necesario que la ley tenga por finalidad el bien común, pues dado que el poder se transmite para el bien común, cuando se legisle hay que buscar ese bien común. ${ }^{61}$ Según Suárez, "la creación de las leyes es el acto principal por el cual se gobierna al Estado y, por lo tanto, las leyes deben tener como fin el bien común". ${ }^{62}$ Así, el bien común es una condición más de validez de la ley, ya que "la ley que no es hecha para el bien común no es ley". ${ }^{63}$

Para Suárez, la ley obliga sólo si se cumplen con las condiciones de validez (causa eficiente, material, formal y final). ${ }^{64}$ De lo contrario, no obliga (y no se debe obedecer), pues en realidad no es una verdadera ley.

En suma, Suárez señala que la causa eficiente de la ley positiva es la autoridad. ${ }^{65}$ De no ser así, esa ley no es válida. Y esto concuerda con lo señalado por el iuspositivismo. Y, particularmente, el de Austin, que hace hincapié en la autoridad. Piénsese, por ejemplo, en México: la ley es válida sólo si

57 Ibidem, I, 1, 6 .

58 Ibidem, I, 9, 13.

59 Ibidem, I, 1, 6.

60 Para los escolásticos, la ley natural es siempre justa y la ley humana se debe ajustar a ella. Es por esta razón que Tomás de Aquino decía que la ley humana debe derivar de la ley natural y, si no es así, no será una ley sino la corrupción de la ley. Véase Tomás de Aquino, S. t., Ia, IIae, 95, 2. Luego de haber citado las palabras de San Agustín ("No parece que sea una ley la que no sea justa"), Tomás de Aquino dice efectivamente que: "toda ley surgida de los hombres no tiene razón de ley más que en la medida en que ella derive de la ley de la naturaleza. Si ella se desvía en algún punto de la ley natural, ya no es entonces una ley, sino una corrupción de la ley". Idem.

61 Suárez, Francisco, De legibus, I, 7, 5.

62 Ibidem, I, 8, 7. Suárez dice también: "El poder de jurisdicción, por su institución originaria, es concedida para el bien de la comunidad". Ibidem, I, 8, 5 .

63 Ibidem, I, 9, 13.

64 Ya mencionado anteriormente, véase ibidem, III, 31, 6.

65 Ibidem, I, 13,1. 
es creada por el Congreso de la Unión, como lo establecen los artículos 71 y 72 de nuestra Constitución.

La causa formal es, de acuerdo con Suárez, "la forma en que la ley se debe hacer y promulgar" ${ }^{66}$ Esto también concuerda con el iuspositivismo, en este caso con Kelsen y Hart, pues no basta con que la autoridad lo dicte: se debe cumplir con las normas que establecen los procedimientos formales de creación del derecho. Por ejemplo, el procedimiento señalado en los mismos artículos ya citados de la Constitución mexicana.

Para la concepción escolástica, el objetivo último del derecho es de carácter moral $\mathrm{y}$, en consecuencia, busca hacer de nosotros buenos ciudadanos y buenas personas y - en todo caso- pretende convertirnos en seres cada vez más libres para emprender mejores decisiones. De hecho, para Suárez, el fin que persigue la ley es hacer buenos ciudadanos: "la ley, para ser ley, debe ser justa; entonces, para ser justa, es necesario que tienda a un fin bueno ligado con el bien común y a través de un medio honesto; en consecuencia, aquel que observa la ley, actuará en el sentido de la honestidad por el bien común; en consecuencia, en virtud de la ley él será bueno" ${ }^{67}$

Quizás, para el lector actual, parezcan irrelevantes estas concepciones escolásticas de la validez del derecho; incluso, para reforzar este escepticismo, se puede señalar que dichas condiciones de validez, vinculadas a la teoría de las causas, destacan por no ser sino una teoría especulativa. Pero es valiosa la observación que con insistencia señala la escolástica: el carácter parcial del iuspositivismo. Dicho de otro modo: el positivismo posee un carácter normativista o formalista (en tanto que reduce el derecho a su forma).

Los criterios de validez del iuspositivismo se circunscriben entonces a las primeras condiciones: causas eficiente y formal. Y en el caso más extremo, el positivismo consagra, como criterio esencial de validez, a la causa eficiente (la autoridad). Para el iusnaturalismo, ambas condiciones constituyen criterios necesarios, pero no suficientes de validez; y el iusnaturalismo no los rechaza, sino que incluso los reconoce y los requiere.

El iuspositivismo afirma que el derecho - tal cual es - se puede desvincular de la moral, en la medida en que la inmoralidad del derecho no afecta su validez. Mientras que el iusnaturalismo, según hemos visto, ha demostrado no sólo alguna forma de vinculación, sino la presencia de principios morales en el derecho, como ocurre con Dworkin.

\footnotetext{
66 Idem.

67 Ibidem, I, 13, 3.
} 
No obstante, la noción de los principios es otra de las contribuciones de la escolástica y de la cual Suárez fue igualmente partícipe. Más allá de la concepción iuspositivista, que reduce el derecho a un sistema de normas, los escolásticos estudiaron muy anticipadamente la existencia de principios en el derecho. Se trató de un planteamiento innovador y los escolásticos fueron de los primeros en dar un lugar preponderante a los principios, entendidos éstos como normas morales que forman parte de los sistemas jurídicos. Se trató, además, de una tendencia dominante por siglos, que sólo fue eclipsada por el positivismo jurídico del siglo XIX y parte del XX, y que sería readmitida gracias - entre otros - a Ronald Dworkin. Pero, como veremos, es ante todo una contribución cuyos orígenes podemos hallar en la escolástica, y que está asociada, de nueva cuenta, al reconocimiento de las relaciones entre el derecho y la moral.

De acuerdo con Jean-Marie Carbasse, los jurisconsultos romanos no consideraban que una regula —o principio - existiera de antemano ni por sí misma. Es decir, una regula no era un principio preestablecido que se imponía a la realidad, sino que la mecánica era justamente la opuesta: a partir de las situaciones jurídicas reales se deducían, con posterioridad, los principios jurídicos. ${ }^{68}$

Del mismo modo, Rolando Tamayo y Salmorán señala que, para los romanos, los primeros principios del derecho no son revelados o descubiertos. ${ }^{69}$ Estos primeros principios reciben el nombre de regulae. Por el contrario, según indica Tamayo y Salmorán, las regulae se extraen del derecho positivo y son válidas únicamente en relación con él. ${ }^{70}$

Carbasse señala que fue Labeón, contemporáneo de Augusto, quien formuló, antes que cualquier otro jurisconsulto, las regulae..$^{71}$ Asimismo, tanto Carbasse como Tamayo y Salmorán citan, por otra parte, la definición de Paulo, contenida en el Digesto, que dice: "La regula es la breve descripción de lo que una cosa es. No es por la regula que el derecho es creado; es del derecho de donde la regula se obtiene. La regula hace una descripción sucinta de las cosas y, como lo afirmaba Sabino, tanta es ésa su razón de ser que si sufre de alguna imprecisión, pierde su función". ${ }^{72}$

68 Carbasse, Jean-Marie, Manuel d'introduction historique au droit, 3a. ed., París, PUF, 2009, p. 62.

69 Tamayo y Salmorán, Rolando, op. cit., p. 146.

70 Idem.

71 Carbasse, Jean-Marie, op. cit., p. 62.

72 D. $50,17,1$. 
Es decir, los romanos desarrollaron generalizaciones a partir de la observación de sus instituciones positivas, explica Tamayo y Salmorán; estas generalizaciones (las definiciones y los conceptos generales) eran la cúspide del sistema teórico; sin embargo, para los romanos, las regulae no estaban por encima del derecho positivo. El derecho no se deriva de las regulae, por el contrario, ellas dependían del derecho positivo. ${ }^{73}$ El giro, no obstante, vino con los escolásticos. Rolando Tamayo y Salmorán explica que:

los juristas medievales del siglo XII transformaron las regulae en principios universales atemporales. [...] No sólo intentaron organizar el sistema jurídico, sino que también asumieron que podían demostrar, con la razón, la verdad universal de los textos romanos. Dado que estos textos son racionalmente demostrados, constituyen maximae propositiones para apodícticamente deducir de ellas nuevas soluciones. Pero como estos textos contenían lacunae, ambiguitates y contradictiones, fue necesario recurrir al razonamiento dialéctico para superarlas. ${ }^{74}$

Así, Tamayo y Salmorán subraya el uso del razonamiento apodíctico y dialéctico en la escolástica. El razonamiento apodíctico es aquel que deriva de premisas que son tenidas como verdades necesarias, mientras que el razonamiento dialéctico es aquel que deriva de premisas generalmente aceptadas. ${ }^{75}$ Por lo tanto, en este giro metodológico realizado en las regulae romanas, los escolásticos hicieron uso del razonamiento apodíctico.

Este problema se asocia con otra noción: la de los derechos subjetivos, la cuestión es si un derecho subjetivo existe sólo en función de lo que dicta una norma de derecho positivo o si, en cambio, existe en función de un principio moral o de una facultad moral inherente al ser humano. Bajo la influencia del positivismo jurídico, se suele estimar que el "derecho subjetivo" existe sólo en función del "derecho objetivo"; en este sentido, el derecho subjetivo se entiende, actual y habitualmente, como la prerrogativa derivada de la norma, mientras que el derecho objetivo es el conjunto de normas que permiten o prohíben conductas específicas. De acuerdo con Eduardo García Máynez:

el derecho subjetivo es una función del derecho objetivo. Este último es la norma que permite o prohíbe; la primera es la permisión derivada de la nor$m a$. El derecho subjetivo no se concibe sin el derecho objetivo, ya que al pre-

\footnotetext{
73 Tamayo y Salmorán, Rolando, op. cit., p. 146.

74 Ibidem, p. 147.

75 Ibidem, p. 144.
} 
sentar la posibilidad de hacer (u omitir) lícitamente algo, supone lógicamente la existencia de la norma que da a la conducta permitida la marca positiva de ser un acto lícito. ${ }^{76}$

A propósito de esta concepción iuspositivista del derecho, Daniel Gutman hace notar que "el derecho subjetivo parece reducirse a una prerrogativa individual concedida a un sujeto de derecho. Se contrapone en esto al derecho llamado 'objetivo', el cual está constituido por reglas de derecho que permiten al sujeto actuar". ${ }^{77}$

El derecho supone, según Tamayo y Salmorán, una reducción de las opciones del comportamiento. ${ }^{78}$ Antes de la imposición de tal reducción - explica-, la conducta es opcional, el sujeto es libre de realizarla u omitirla; a ello, Tamayo y Salmorán da el nombre de permisión, en un sentido amplio, ya que el comportamiento no está prohibido. Pero también distingue la existencia de una permisión propiamente dicha: el comportamiento está permitido debido a un derecho establecido para ese propósito. La permisión propiamente dicha recibe el nombre de derecho subjetivo. ${ }^{79}$

"De lo anterior [agrega Tamayo y Salmorán] se sigue que el derecho subjetivo presupone, siempre, una fuente que lo establece. Sobre el particular permítaseme señala lo siguiente: un derecho (subjetivo) existe si, y sólo si, hay una fuente que determine su contenido y existencia". ${ }^{80}$ Podemos ver que - según estos autores - un derecho cuyo contenido corresponda a lo que se denomina "derecho subjetivo" no es una prerrogativa inherente al ser humano. Tanto para los teóricos iuspositivistas contemporáneos como para los juristas de la antigua Roma, un derecho existe únicamente gracias al derecho objetivo.

Sin embargo, como Rolando Tamayo y Salmorán lo ha mencionado, una concepción opuesta fue desarrollada: él indica que el derecho no sólo debe ser concebido como un orden imperativo que impone obligaciones (y sanciones), sino que también puede ser entendido en términos de derechos. ${ }^{81}$

Si el giro a la noción romana de regula fue realizado por la escolástica en el siglo XII, en cambio, la noción de derecho subjetivo, propiamente

\footnotetext{
76 García Máynez, Eduardo, Introducción al estudio del derecho, México, Porrúa, 1984, p. 36.

77 Gutmann, Daniel, “Droit subjectif”, en Alland, Denis y Rials, Stéphane (eds.), op. cit., p. 530.

78 Tamayo y Salmorán, Rolando, El derecho y la ciencia del derecho. Introducción a la ciencia jurídica, México, UNAM, Instituto de Investigaciones Jurídicas, 1986, p. 25.

79 Ibidem, p. 66.

80 Ibidem, p. 68.

81 Ibidem, p. 67.
} 
dicha, fue concebida por primera vez también por la escolástica, pero en el siglo XIV, por Guillermo de Ockham, ${ }^{82}$ y posteriormente fue desarrollada por la escolástica española, así como por Grocio y Pufendorf. John Doyle afirma que "en el contexto de los debates medievales sobre el juramento de pobreza, Ockham y otros autores franciscanos conciben el derecho como un poder legítimo que reside en el ser humano de cara a la autoridad a la cual está sometido". ${ }^{83} \mathrm{Al}$ respecto, Samuel Antonio González Ruiz señala:

originalmente el derecho subjetivo se correspondía con lo que pertenecía al individuo y, por lo tanto, con lo que podía defender legítimamente. Grocio y Pufendorf, siguiendo esta tendencia, estimaron el derecho subjetivo como una 'prerrogativa moral' basada en el individuo y en el contrato social; si el hombre tuvo que compartir sus derechos con la sociedad para vivir en comunidad, se reserva ciertos derechos que le permiten exigir moralmente el cese de cualquier abuso. En el iusnaturalismo, el argumento según el cual los derechos subjetivos surgen de normas de un orden superior, y que el orden jurídico positivo debe protegerlos so pena de no ser obligatoria, es clásico. ${ }^{84}$

Desde la perspectiva iusnaturalista, la operación es, por lo tanto, inversa: el derecho objetivo depende de los principios que subyacen en los derechos subjetivos; esos derechos, inherentes al ser humano, son la encarnación de principios con un valor moral, tales como la justicia, la dignidad, la libertad o la igualdad; en Suárez, el derecho subjetivo recibe el nombre de "facultad moral"; de hecho, al abordar el concepto de derecho (ius), lo distingue en dos sentidos: por una parte, como un conjunto de normas de un sistema jurídico y, por otra, como una facultad moral. Suárez dice: "De acuerdo con este último y estricto significado, ius es rigurosamente hablando la facultad moral que tenemos sobre lo que es nuestro o lo que se nos debe. Por lo tanto, el propietario de una cosa tiene derecho sobre la cosa y un empleado tiene derecho al salario, y por ello afirmamos que merece su retribución". ${ }^{85}$

En este ejemplo que señala Suárez, el derecho de propiedad y el derecho al trabajo (con su salario respectivo) son una facultad moral e inherente; la facultad moral (derecho subjetivo) no deriva su existencia, del derecho positivo. De igual manera, explica que los dos sentidos de la palabra derecho,

82 Doyle, John, "Francisco Suárez, S. J. on Human Rights", en Wegmann, Konrad et al., Menschenrechte: rechte und Pflichten in Ost und West, Munster, Lit Verlag, 2001, p. 116.

83 Idem.

84 González Ruiz, Samuel Antonio, "Derecho subjetivo", Diccionario jurídico mexicano, México, UNAM, Instituto de Investigaciones Jurídicas, 1982, t. III, p. 206.

85 Suárez, Francisco, De legibus, I, 2, 5. 
como facultad moral (derecho subjetivo) y como conjunto de normas (derecho objetivo), pueden ser nombrados de otro modo; al derecho subjetivo se le puede llamar derecho "útil" y al derecho objetivo, derecho "legal"; ambos se dividen, a su vez, en derecho natural, en derecho de gentes y en derecho civil. Sostiene así lo siguiente: "Se denomina derecho natural útil cuando se da por la naturaleza misma o cuando viene con ella: la libertad, así, tiene sus raíces en el derecho natural". ${ }^{86}$

Así pues, encontramos en Suárez una idea muy presente: el ser humano cuenta con facultades morales, con derechos subjetivos; estos derechos no derivan de ningún derecho positivo, y existen con antelación a cualquier ordenamiento en tanto que están asociados a ciertos valores morales o principios inherentes a la naturaleza humana. De hecho, los textos de este autor están colmados de principios; dice, por ejemplo, que la esclavitud deriva del derecho de gentes (como institución de derecho positivo compartida por la mayoría de los pueblos); señala que no es una institución del derecho natural, pues somos libres por naturaleza: "el hecho de estar libre de la servidumbre es una propiedad natural del hombre y por eso decimos que es un derecho natural". ${ }^{87}$ Además, Suárez sostiene que somos libres, en razón, de "la dignidad natural del hombre. Porque el hombre, creado a imagen de Dios, ha sido creado independiente, y sujeto sólo a Dios", y concluye: "por lo tanto, no parece que pueda ser reducido a la esclavitud por otro hombre". ${ }^{88}$

\section{CONCLUSIÓN}

Nuestra admiración por los pensadores contemporáneos, como Dworkin o Finnis, no es desmedida; al contrario, creo que está enteramente justificada; sus textos están llenos de aciertos y ofrecen claridad en muchas de las polémicas jurídicas contemporáneas; han aportado soluciones que antes, bajo el influjo iuspositivista, parecían difíciles de concebir. Sin embargo, al releer a Suárez debemos reconocer que ellos en realidad forman parte de una larga tradición de pensadores iusnaturalistas; nuestro autor es un buen ejemplo (si no es que uno de los mejores) en este sentido: la crítica a la idea de que el derecho es un mero sistema de reglas y, por lo tanto, la defensa de que el derecho está asimismo compuesto por principios, son argumentos presentes

\footnotetext{
86 Ibidem, II, 17, 2.

87 Ibidem, III, 3, 7.

88 Suárez, Francisco, Defensio fidei, III, 1, 2.
} 
desde hace siglos. Lo mismo ocurre con la obediencia y las razones para desobedecer el derecho; con vinculación entre el derecho y la moral; con la identificación del bien o la verdad en la moral asociada a la racionalidad humana. Son ideas, insisto, con una historia muy extensa.

Una diferencia muy importante, entre Suárez y el caso particular de Dworkin, se halla, sin embargo, en que Dworkin renuncia a toda explicación metafísica (es decir, a Dios) para dar cuenta de su teoría del derecho. Además, ha hecho una labor extraordinaria al demostrar mediante casos judiciales muchas de las premisas de la filosofía iusnaturalista (algo que habría sido imposible de exigir a Suárez cuando vemos el rol que juegan los jueces en las sociedades democráticas de la actualidad) y, por lo tanto, ha contribuido sobradamente a criticar la idea preconcebida de que la filosofía jurídica sólo se ocupa de simples elucubraciones sin aplicación práctica.

Otro aspecto que escapó al pensamiento suareciano fue el carácter liberal del mundo moderno, en el sentido de privilegiar la vida privada sobre los asuntos públicos, y en el sentido de limitar el poder público al respeto de esos derechos subjetivos, privados e individuales. Pero esta noción liberal y moderna del poder no habría sido posible sin las contribuciones previas de la escolástica: Suárez teorizó sobre la validez del derecho, la desobediencia, los abusos del poder, el tiranicidio y el poder que reside en el pueblo. Se trata, pues, de un conjunto de ideas que compartimos y que hemos sido capaces de difundir a lo largo de siglos, y del cual Suárez es parte: el pensamiento jurídico moderno.

Ante la actual oleada de regímenes populistas y de democracias iliberales, se vuelve necesario revisitar no solamente los orígenes del liberalismo y de las democracias, sino también los fundamentos filosóficos de los derechos humanos y las raíces morales del derecho en autores como Francisco Suárez. 